\title{
Serological Investigation and Molecular Characterization of Reticuloendotheliosis Virus from Breeder Flocks in Pakistan by Polymerase Chain Reaction
}

\begin{abstract}
Arooj Sattar, Farheen Ansari
ABSTRACT

OBJECTIVE: The goal of this study was to provide the authentic information about the incidence of reticuloendotheliosis virus in Pakistan because several epidemiological studies suggested a link between avian oncogenic viruses and different types of cancers in people working in poultry industry. METHODOLOGY: Cross sectional study to determine the REV infection status. Presence of antibodies in serum were observed using ELISA and confirmation of REV genome was made by polymerase chain reaction using long terminal repeat specific primers to amplify a $291 \mathrm{bp}$ fragment of REV viral genome from tumor samples of liver collected from breeder flocks with average age of 30 weeks. In all 480 serum and liver samples were taken from 24 poultry breeder across Punjab and Khyber Pakhtunkhwa.

RESULTS: Out of $\mathbf{4 8 0}$ serum samples $\mathbf{4 2}$ serum samples which were found positive for REV antibodies by ELISA. When subjected to PCR revealed $n=37$ to bear REV genome.

CONCLUSION: It is concluded that reticuloendotheliosis virus is present in breeder flocks across a wide range of area across Pakistan which can be hazardous to public health.
\end{abstract}

KEY WORDS: Reticuloendotheliosis virus, Polymerase chain reaction, Pakistan

This article may be cited as: Arooj Sattar, Farheen Ansari. Serological Investigation and Molecular Characterization of Reticuloendotheliosis Virus from Breeder Flocks in Pakistan by Polymerase Chain Reaction. J Liaquat Uni Med Health Sci. 2018;17(03):141-6. doi: 10.22442/jlumhs.181730566

\section{INTRODUCTION}

Reticuloendotheliosis virus is a retrovirus. Retroviruses are enveloped RNA viruses. They integrate themselves into the host's cell genome which aids in their detection from the genome of host's cell DNA. They replicate by RNA dependent reverse transcription. REV group is divided into two groups. REV replication defective strain $T$ and REV non defective strain A. REV T strain infects avian species and has the most oncogenicity, causes tumors of spleen and kidney ${ }^{1}$.

Indigenous and spontaneous infection of REV is seen in many avian species such as chicken, Japanese quail, turkeys, pheasants, geese and ducks. Cases of reticuloendotheliosis in avian species were observed throughout the world. Its frequency is increasing day by day as there is no such vaccine available ${ }^{2}$.

Reticuloendotheliosis virus is transmitted vertically, horizontally, by vector and through contaminated vaccines. The most important source of spread of REV which has been reported, is by the unintended and incidental contamination of vaccines especially Marek's disease and fowl pox disease vaccines by reticuloendotheliosis virus ${ }^{3}$. Many economic losses of poultry flocks were noted and proclaimed due to REV contaminated vaccines.

Reticuloendotheliosis is a neoplastic condition which is of great commercial and economic importance. Reticuloendotheliosis is responsible for inducing various disease syndromes which includes most importantly runting disease syndrome, immunosuppression and lymphoproliferative disorders and lymphomas. Runting syndrome is a group of diseases in which a majority of chickens in the poultry flocks are of smaller size than normal. It is due to inappropriate growth. Thus the flock's average weight is markedly low. It is also characterized by slow and abnormal feathering, broken feathers also referred to as helicopter feathers ${ }^{4}$. Diarrhea is also seen. It is mostly due to the REV non defective $T$ strain. When REV infection occurs at an early age, it is responsible for producing $T$ cell and $B$ lymphomas especially with non -defective strain $T$. Lymphomas of B cell origin are reported to be produced by REV non defective strain (REV-T) Due to conflicting and cofounding pathogenesis and pathology associated with 
neoplastic diseases of birds e.g. Marek's disease, avian leucosis and reticuloendotheliosis, polymerase chain reaction (PCR) gives the most definitive affirmation in the diagnosis of REV ${ }^{5}$.

Common antigenicity has been discovered between the glycoprotein antigens obtained from neoplasms of chickens and antigens obtained from variety of human cancers. This suggests that retroviruses are possible etiological agents in human cancers ${ }^{6}$.

\section{Goals of Study}

This research will give the evidence about the infectious disease under study, provide the authentic information about incidence and will guide the veterinary experts and risk management authorities to diagnose this emerging virus in the flocks so that prevention and control measures should be practiced.

\section{METHODOLOGY}

This cross-sectional study was conducted at Institute of Molecular Biology and Biotechnology (IMBB department), The University of Lahore. It was an approved project of IMBB department, UOL. Study was carried out during September 2016 - April 2017.

\section{Inclusion Criteria}

Samples were collected from those breeder flocks that had mortality rates greater than $5 \%$ and showed depressed growth, abnormal feathering, decreased hatchability and neoplastic changes in visceras. There was no epidemic at the time of sample collection.

\section{Exclusion Criteria}

Samples were not collected by those flocks whose mortality rates were less than $5 \%$ and did not show the characteristic symptoms of reticuloendotheliosis virus.

\section{Sample Collection}

Simple Random Sampling technique was used in two steps. In first step breeder farms were randomly selected from Punjab and KPK and in second step the diseased chickens were randomly selected from those breeder farms. Serum and liver samples $n=480$ each were collected during the months of September 2016 - December 2016 randomly from chickens of poultry breeder farms which showed depressed performance and neoplastic lesions in visceras. There was no epidemic at that time. Total 300 samples were collected from Punjab and 180 from KPK. The average age of those flocks was 30 weeks. Diseased chickens $n=20$ were separated from each flock and their serum and liver samples were taken for the detection of REV antibodies for ELISA and molecular characterization by PCR respectively ${ }^{6}$.

Detection of Antibodies to Rev By Elisa

The serum samples were tested for REV antibodies by ELISA using REV antibody Test kit (IDEXX laboratories). ELISA was performed according to the instructions provided in the manual. If the S/P value (sample to positive ratio) was greater than 0.50 (SP $>0.50$ ) the result was considered positive. For precision of results samples were run in duplicates ${ }^{7}$.

\section{MOLECULAR CHARACTERIZATION OF REV} Inclusion Criteria for Molecular Characterization Only those samples were processed for molecular characterization whose serum counterparts were positive for REV antibodies by ELISA ${ }^{4}$

\section{DNA Extraction from Liver Samples}

DNA was extracted from liver samples for the molecular characterization by PCR. DNA was extracted by using QIAamp DNA mini kit (QIAGEN). This kit is designed for quick and effective purification of genomic.DNA from frozen tissue samples. The extracted DNA was then stored at $-20^{\circ} \mathrm{C}^{2}$.

\section{Polymerase Chain Reaction}

The primers were used against the long terminal repeat regions (LTR) of REV genome. Primers were used to amplify a $291 \mathrm{bp}$ amplicon of LTR of REV genome. The primers used for this purpose were (5'-CATACCTGCAGCCAATGGTT-3') and (3' AATGTTGTACCGAAGTACT-5'). The Genbank accession no followed was $\mathrm{KX} 278301^{8}$.

PCR reaction was performed in a $50 \mu$ l reaction mixture, containing $5 \mu \mathrm{L}$ PCR buffer, $3 \mu \mathrm{L} \mathrm{MgCl}_{2}, 1 \mu \mathrm{L}$ dNTPs, each primer $1 \mu \mathrm{L}$, Taq DNA polymerase (Fermentas) $1 \mu \mathrm{L}$ and $1 \mu \mathrm{L}$ template DNA PCR conditions in the thermal cycler (Applied Biosystems 2720) were: initial denaturation at $95^{\circ} \mathrm{C}$ for 5 minutes; 32 cycles of denaturation at $95^{\circ} \mathrm{C}$ for 30 seconds; annealing at $55^{\circ} \mathrm{C}$ for 1 minute; primary extension at $72^{\circ} \mathrm{C}$ for 1 minute; final extension at $72^{\circ} \mathrm{C}$ for 6 minutes and final hold at $4^{\circ} \mathrm{C}$.After completion of polymerase chain reaction the samples were loaded on the gel. Each well was loaded with $7.5 \mu \mathrm{L}$ of sample alongside 3-5 $\mu \mathrm{L}$ of $100 \mathrm{bp}$ DNA ladder or marker. Gel was run at 120 volts for 40 minutes in gel electrophoresis instrument and then visualized by UV transilluminator ${ }^{8}$.

\section{RESULTS}

Out of the Four Hundred and Eighty serum samples Forty two were found positive for REV antibodies on ELISA and genomic DNA was identified in 37 samples using polymerase chain reaction. Percentages were calculated using SPSS $\vee 21$ according to area wise positive isolates.

TOTAL NO OF POSITIVE SAMPLES FOR REV ANTIBOIDIES ON ELISA

Of all Forty two were found positive for REV 
TABLE I: DETAILS OF FLOCKS, TOTAL NO OF SAMPLES AND NUMBER OF POSITIVE SAMPLES

\begin{tabular}{|l|l|l|l|r|r|r|r|r|}
\hline $\begin{array}{c}\text { Farm } \\
\text { no }\end{array}$ & Area & District & Province & $\begin{array}{c}\text { Age of } \\
\text { flock }\end{array}$ & $\begin{array}{c}\text { Total no of } \\
\text { samples }\end{array}$ & $\begin{array}{c}\text { Positive samples } \\
\text { on ELISA }\end{array}$ & $\begin{array}{c}\text { Percentage of } \\
\text { positive isolates }\end{array}$ & $\begin{array}{c}\text { Mortality } \\
\text { rates }\end{array}$ \\
\hline 1 & Pattoki & Kasur & Punjab & 27 weeks & 20 & 8 & $40 \%$ & $7 \%$ \\
\hline 2 & Behali & Mansehra & KPK & 34 weeks & 20 & 15 & $75 \%$ & $21 \%$ \\
\hline 3 & Sherwan & Abottabad & KPK & 38 weeks & 20 & 19 & $95 \%$ & $30 \%$ \\
\hline
\end{tabular}

TABLE II:

\section{ELISA RESULTS OF THE POSITIVE SAMPLES}

\begin{tabular}{|c|c|c|c|}
\hline Sample No & SP Ratio & Sample No & SP Ratio \\
\hline 1. & 8.917 & 22. & 1.328 \\
\hline 2. & 6.321 & 23. & 2.543 \\
\hline 3. & 5.216 & 24. & 7.961 \\
\hline 4. & 1.397 & 25. & 5.552 \\
\hline 5. & 2.544 & 26. & 3.606 \\
\hline 6. & 3.890 & 27. & 2.371 \\
\hline 7. & 4.578 & 28. & 9.846 \\
\hline 8. & 6.552 & 29. & 1.254 \\
\hline 9. & 4.310 & 30. & 1.987 \\
\hline 10. & 7.358 & 31. & 5.364 \\
\hline 11. & 4.695 & 32. & 4.212 \\
\hline 12. & 2.361 & 33. & 7.457 \\
\hline 13. & 12.115 & 34. & 2.981 \\
\hline 14. & 5.961 & 35. & 2.397 \\
\hline 15. & 2.367 & 36. & 5.006 \\
\hline 16. & 4.211 & 37. & 4.070 \\
\hline 17. & 8.312 & 38. & 1.798 \\
\hline 18 & 4.555 & 39. & 3.432 \\
\hline 19. & 5.639 & 40. & 3.257 \\
\hline 20. & 3.746 & 41. & 4.147 \\
\hline 21. & 1.264 & 42. & 2.305 \\
\hline
\end{tabular}

antibodies on ELISA. Eight samples were positive out of 20 samples from a poultry breeder flock from Pattoki, Kasur ( $40 \%$ positive isolates), 15 serum samples were positive out of 20 from a poultry breeder flock from Behali, Mansehra ( $75 \%$ positive isolates) and 19 serum samples were positive on ELISA from a breeder flock from Abottabad, KPK (95\% positive isolates). Details of flocks, total no of samples and no of positive samples are listed in Table I. Values of sample to positive ratios (SP values) determined as mean of optical absorbances are given in Table II. The value if was greater than 0.50 declared a positive result on ELISA.

\section{TOTAL NO OF SAMPLES POSITIVE ON PCR}

DNA was extracted from liver samples and molecular characterization was done by polymerase chain reaction. Out of Forty two samples found positive by ELISA the genomic DNA was identified in 37 samples. Results received upon gel electrophoresis are shown in the figures 1, 2 and 3. The figures show the bands of LTR fragments of REV genome (291bp) as discrete bands.

\section{PROVINCE WISE COMPARISON OF REV}

Out of Four Hundred and Eighty samples Three hundred samples were taken from Punjab and One Hundred eighty from KPK. Out of Three hundred samples from Punjab 8 samples were found to posses REV antibodies (2.7\% positive isolates). Out of One hundred eighty samples from KPK 34 samples were found positive for REV antibodies (18.9\% positive isolates). The data shows the incidence of REV to be higher in KPK than in Punjab.

Figure I: Appearance of bands of LTR fragment of REV genome (291bp) on gel electrophoresis.

Lane M : Moleular marker (100 bp DNA ladder); Lane 1-14: Samples

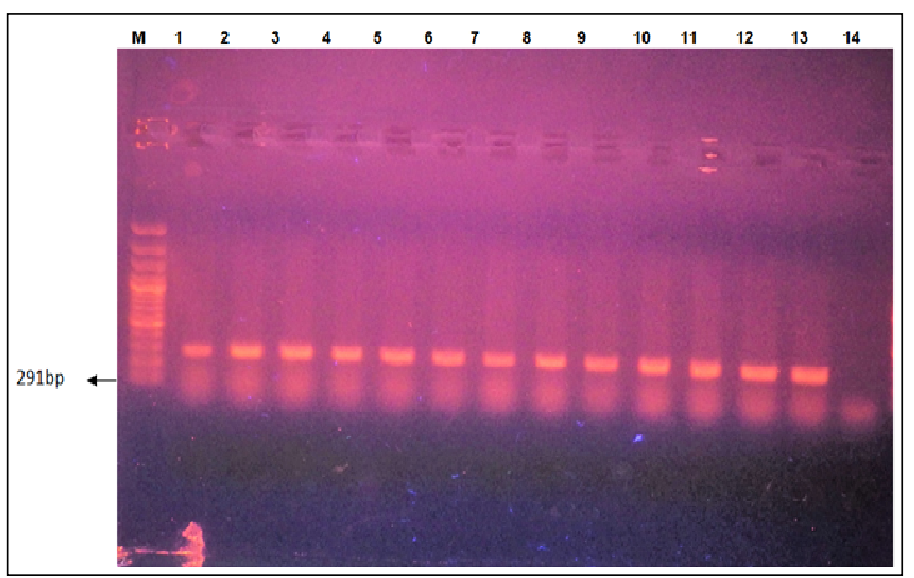


Figure II: Appearance of bands of LTR fragment of REV genome (291bp) on gel electrophoresis. Lane M : Moleular marker (100 bp DNA ladder); Lane 1528 : Samples

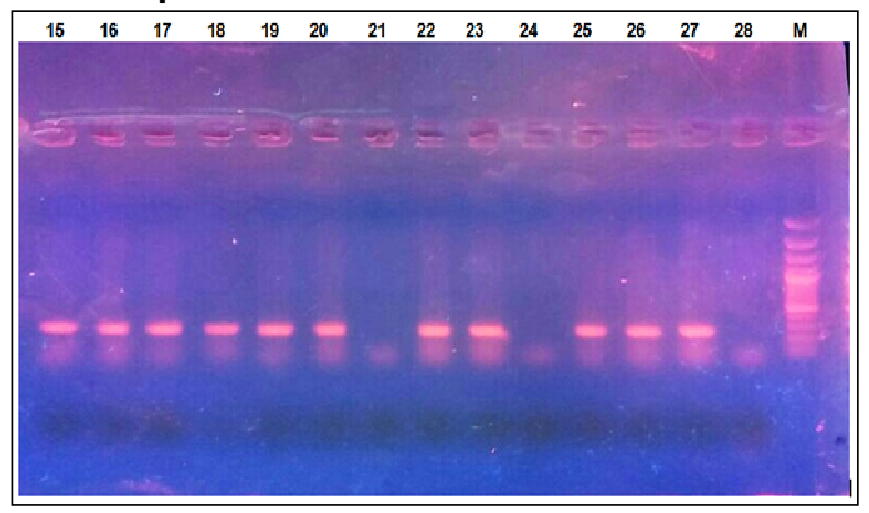

Figure III: Appearance of bands of LTR fragment of REV genome (291bp) on gel electrophoresis. Lane M : Moleular marker (100 bp DNA ladder); Lane 29-42: Samples

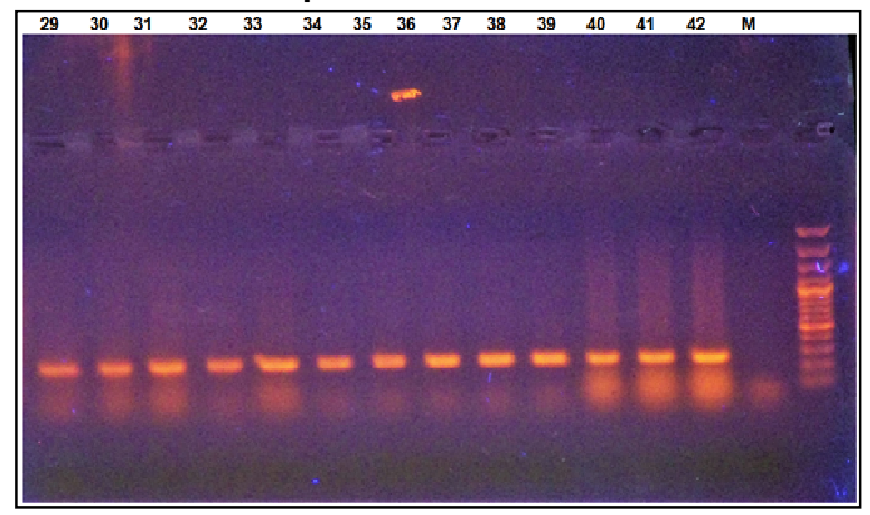

\section{DISCUSSION}

In this study the signs and symptoms that were typical to REV were detected and were noted in chickens in breeder flocks at an average age of 32 weeks. In general this study shows the presence of REV in Pakistan. Although the incidence is higher in KPK than Punjab but the significant presence of reticuloendotheliosis virus in samples from Punjab cannot be ruled out.

Liver samples taken from diseased chickens were investigated by PCR for the presence of REV genome. Amplification product at $291 \mathrm{bp}$ was indicative of the REV genome. These assays are the diagnostic tools in active REV infection that causes runting disease syndrome and immunosuppression with high mortality and morbidity. There are other techniques e.g. immunohistochemistry and viral isolation which are diagnostic for detection of REV but PCR is the most sensitive and specific $^{9}$. This study provides the specific results about the prevalence of REV virus in chickens in breeder farms in Pakistan.
This study reveals that the age at which REV virus infects birds is between 25-35 weeks and older the flock age the more is the infection and the mortality rate as shown by the results. In Farm 1 (age 27 weeks) $40 \%$ positive isolates were detected and mortality rate was $7 \%$, Farm 2 (age 34 weeks) showed $75 \%$ positive isolates and the mortality rate was $21 \%$ whereas the highest infection rate was found from Farm 3 (age 38 weeks), 95\% positive isolates and 30 $\%$ mortality rate. This shows that REV infection is more severe in older flocks. These results are in harmony with the studies done by Yang et al. which showed that the sero-prevalence of REV increased with increasing age of the flock but not immediately after the administration of Marek's disease and fowl pox disease vaccines, whereas the study done by Wei et al. illustrated the outbreak of REV infection in young flocks which revealed that the infection of REV in young chickens was most probably due to administration of REV contaminated vaccines or by congenital transmission. Flocks that were found positive for REV in our study were of older age, thus the exposure of REV was assumed to come from environment because it was impossible to have such high maternal antibodies level for all of them as they were more than 25 weeks old and the vaccines used in these flocks had no storage and can't be verified one by one and the infection caused by contaminated vaccines was detected in young flocks ${ }^{2}$.

In this study we also observed that although 3 breeder flocks were found positive for REV antibodies, but their positive rates were quite different from each other as the lowest positive rate was $40 \%$ for Farm 1 and the highest positive rate was 95\% for Farm 3 was observed. This may be related to the susceptibility to REV of different native chickens or the situation in different regions of Punjab and KPK. These results correlate with the results of study done in native chicken flocks in China.

Due to financial crisis faced by poultry industry, this study aimed to provide information about this newly emerging virus in Pakistan which will help in the management authorities to not only diagnose it timely but it will also save the foreign exchange which is being spent on the definitive diagnosis of the infections in poultry. These viruses have been shown to be capable of infecting human cells invitro and induce neoplastic changes. Studies also showed that poultry workers and subjects in general population are commonly infected with these viruses and there viruses are responsible of the development of cancers of major sites i.e cancers of buccal and nasal cavities, rectum and esophagus, pacreas, trachea, lungs, brain, ovary and tumors of hmopoeitic system ${ }^{11}$. These risks were not limited to cancers only but 
neurological disorders and dieases of cardiovascular and urinary systems were also detected.

\section{CONCLUSION}

From this study it is concluded that reticuloendotheliosis virus is present in poultry breeder farms in some of the regions of Pakistan and is one of the cause of mortality and morbidity. The study shows some numbers of confirmed cases of REV, which though are significant, are still lower than the suspected ones. The findings of this study gives the sufficient information that will guide the poultry industry officials about the presence of this newly emerging virus so efforts may be made for its prevention and control and direct steps should be taken to look after the poultry workers during carrying out tasks that put them on risk of exposure to the infectious agents. Another important implication of this study is that the general population may be at risk of developing neoplasms from exposure to live poultry or their products or by ingesting raw meat or by receiving contaminated vaccines with poultry oncogenic viruses.

\section{RECOMMENDATIONS}

The poultry industry is a backbone of farming in Pakistan with a substantial impact on state's GDP which is $1.3 \%^{12}$. It has a major influence in the economy of Pakistan but nowadays it has been facing serious challenges due to outbreaks of infectious diseases which confer economic losses are mostly caused by viruses including certain uncommon and unknown ones such as REV. Hence, future studies may be directed to check the prevalence and clinical outcomes of REV on a larger sample size and may be at other or different time of the year. Molecular characterization through genome sequence analysis of the virus strain shall provide information about the strains prevalent in the region (Pakistan) and preparation of vaccines against these indigenous strains for effective control as they infect a wide avian host range ${ }^{13}$. Its potential to exist as a provirus with other viruses is yet another point to consider the REV seriously ${ }^{14}$. Future studies are immediately required to investigate that possibility of avian oncogenic viruses to present as a public health problem

\section{REFERENCES}

1. Koo BS, Lee HR, Jeon EO, Jang HS, Han MS, Min KC, et al. An Outbreak of Lymphomas in a Layer Chicken Flock Previously Infected with Fowlpox Virus Containing Integrated Reticuloendotheliosis Virus. Avian Diseases 2013; 57(4):812 -817. https://doi.org/10.1637/10551-041113Case.R1
2. Yang Y, Zhao J, Ma Z, Xu M, Xue J, Zhang G. Serological survey of Reticuloendotheliosis virus infection in chickens in China in 2005 to 2015. Poult Sci 2017; 96(11):3893-3895. doi: 10.3382/ps/pex209.

3. Li J, Dong X, Yang C, Li Q, Cui Z, Chang S, et al. Isolation, identification, and whole genome sequencing of reticuloendotheliosis virus from a vaccine against Marek's disease. Poultry Science 2015; 94(4):643-649. http://dx.doi.org/10.3382/ps/ pev034

4. El-Sebelgy MM, Ahmed BM, Ata NS, Hussein HA. Molecular detection and characterization of reticuloendotheliosis virus in broiler breeder chickens with visceral tumors in Egypt. IJVSM 2014; 2(1):21-26. https://doi.org/10.1016/ j.ijvsm.2013.12.005

5. Niewiadomska AM, Gifford RJ. The Extraordinary Evolutionary History of the Reticuloendotheliosis Viruses. PLoS Biology 2013; 11(8):e1001642. doi. $10.1371 /$ journal.pbio. 1001642

6. Bangara S, Felini M, Aryal S, Sterling D, Johnson E. Risk of hematopoietic cancer associated mortality among workers in the poultry slaughtering and processing industries. American Association for Cancer Research, AACR Special Conference on Hematologic Malignancies: Translating Discoveries to Novel Therapies, Philadelphia, September 21, 2014. Clinical Cancer Research 2015; 21(17): A27.

7. Qamar MF, Aslam H, Liaqat A. Haematological Studies on Stunting Syndrome in Broilers. Res J Vet Pract 2015; 3(1):19-24. doi: http:// dx.doi.org/10.14737/journal.rjvp/2015/3.1.19.24

8. El-Abasy MA, El-Gohary A, El-Sawy A, Hafez HM, El-Adawy $H$. Histopathological and Serological Diagnosis of Avian Reticuloendotheliosis in Cross-bred Chicken Farms in Delta Egypt. AJAVA 2016; 11(5): 272-279.

9. Awad AM, Abd El-Hamid HS, Abou Rawash, AA, Ibrahim $\mathrm{HH}$. Detection of reticuloendotheliosis virus as a contaminant of fowl pox vaccines. Poultry Science 2010; 89(11): 23892395. https://doi.org/10.3382/ps.2010-00899.

10. Li J, Yang C, Li Q, Li H, Xia Y, Liu D, et al. Complete Genome Sequence of Reticuloendotheliosis Virus Strain MD-2, Isolated from a Contaminated Turkey Herpesvirus Vaccine. Genome Announc 2013; 1(5):e00785-13-e0078513. doi.10.1128/genomeA.00785-13.

11. Johnson ES, Felini M. Cancer risks in workers exposed to oncogenic viruses. The National Institute for Occupational Safety and Health (NIOSH) R01-OH-008071, 2017; 1-31

12. Hussain J, Rabbani I, Aslam S, Ahmad HA. An 
overview of poultry industry in Pakistan. World's Poult Sci J 2015; 71(4):689-700. doi.101017/ S0043933915002366.

13. Sun G, Zhang Y, Zhou L, Lv H, Zhang F, Li K, et al. Co-Infection with Marek's Disease Virus and Reticuloendotheliosis Virus Increases Illness Severity and Reduces Marek's Disease Vaccine
Efficacy. Viruses 2017; 9(6):158. doi.10.3390/ v9060158

14. Devlin JM, Vaz PKO, Coppo MJ, Browning GF. Impacts of poultry vaccination on viruses of wild bird. Curr Opin Virol 2016; 19:23-9. doi: 10.1016/ j.coviro.2016.06.007.

\section{AUTHOR AFFILIATION:}

Dr. Arooj Sattar (Corresponding Author)

Senior Demonstrator, Department of Pathology

Central Park Medical College Lahore, Punjab-Pakistan.

Email: draroojsattar@gmail.com

\section{Dr. Farheen Ansari}

Associate Professor

Institute of Molecular Biology and Biotechnology

The University of Lahore, Punjab-Pakistan. 